\title{
Codetermination, price competition and the network industry
}

\section{Luciano Fanti • Luca Gori}

Date of submission: July $9^{\text {th }}, 2018$

\begin{abstract}
This research develops a tractable two-stage duopoly game describing the behaviour of price-setting firms that must choose to be profit maximisers or bargainers under codetermination in a network industry with horizontal product differentiation. The existing theoretical literature has already shown that codetermination might arise as the endogenous market outcome in a strategic competitive quantity-setting duopoly. In sharp contrast with this result, the present article shows that codetermination does never emerge as a Nash equilibrium in a price-setting non-network duopoly. Then, it aims at highlighting the role of network externalities in determining changes of paradigm of the game and letting codetermination become a sub-game perfect Nash equilibrium when prices are strategic substitutes or strategic complements. This equilibrium may be Pareto efficient.
\end{abstract}

Keywords Codetermination; Network externalities; Price competition

JEL Classification D43; J53

L. Fanti

Department of Economics and Management, University of Pisa, Via Cosimo Ridolfi, 10, I-56124 Pisa (PI), Italy e-mail: luciano.fanti@unipi.it

tel.: +390502216369; fax: +390502210603

L. Gori (corresponding author)

Department of Law, University of Pisa, Via Collegio Ricci, 10, I-56126 Pisa (PI), Italy

e-mail: luca.gori@unipi.it or dr. luca.gori@gmail.com

tel.: +390502212847. 


\section{Introduction}

There exists an increasing attention to the institution of codetermination in several countries of Western Europe. Codetermination implies, broadly speaking, that employees' representatives sit on the supervisory board in large companies and they participate at several decisions at both the establishment and workplace levels, especially those regarding employment. Such an institution is a relevant feature of the German industry, but it is widespread also in other European countries. Comprehensive legislation on board-level representation can be found in as Austria, Denmark, Finland, France, Luxembourg, the Netherlands, Norway and Sweden (Schulten and Zagelmeyer, 1998). ${ }^{1}$ However, the German system remains the most interesting and complex one. Although both the rules to setting works councils and specific laws on establishment and workplace codetermination have changed several times since their introduction, ${ }^{2}$ by favouring or discouraging - as swings of a legislative pendulum - the formation and competence of work councils, the German system of codetermination has often been regarded as an example. Indeed, it has become increasingly important especially in recent decades due to the worldwide diffusion of the decline in private-sector union density, representing an exemplary system able to provide a potential solution to the problem of sub-optimal worker involvement hinted at by the facts of union decline. The European Union $^{3}$ has referred to the German institution in its enduring political debate on the designing of various systems seeking to increase worker participation. This is shown by the Davignon report published on October 27 th 1970 by the European Commission (see Schulten and

\footnotetext{
1 To show the empirical relevance of codetermination, it suffices to note that, amongst the 16 countries covered by European Industrial Relations Observatory (EIRO), only the UK stands alone in having no statutory form of board-level representation or significant collectively agreed provisions. Differently, in countries such as Belgium and Italy there is no general legislation or widely applicable collective agreements providing for board-level representation. However, there exist specific provisions for board-level employee representatives in some public companies (e.g., the state railway in Belgium and a number of state holding companies in Italy).

${ }^{2}$ In 1848, the Frankfurt Parliament started thinking about the development of specific workers' councils for industry organisations to bound corporate power in large companies. In 1920, the Betriebsrätegesetz (Works Council Act) established that firms with more than 20 employees should compulsory introduce consultative bodies to represent the economic interest of workers. In 1951, the Montan-Mitbestimmungsgesetz (Coal, Steel and Mining Codetermination Law) introduced codetermination in firms with more than 1,000 employees to protect workers' rights through the (nearparity) participation of workers' representatives at the supervisory boards.

${ }^{3}$ Even the United States has considered works councils according to the German pattern, as shown by, for example, the deliberations of the Dunlop Commission (1994).
} 
Zagelmeyer, 1998) and more recently by the legislation establishing a general framework for determining minimum information and consultation rights for workers at the workplace (Official Journal, March 2002).

Also, in the German political debate, much (sometimes rather critical) attention was paid to codetermination. For instance, it has been argued that codetermination at the establishment level was under-provided by the market despite the mandatory (but not automatic) legislation, and that changes regarding the structure and functioning of codetermination were required to improve its economic performance (Kommission Mitbestimmung, 1998). ${ }^{4}$ Together with the latter argument, there were also demands from the union movement for reforming it, with the consequence of a new Works Constitution Act in July 2001 aiming at increasing the influence of the works council in Germany.

On theoretical grounds, McCain (1980) provided the first contribution in the economic literature about codetermination aiming at setting up a rigorous framework to set out a theory of the organisation of the firm and explain their behaviour when control is shared between the workers and shareholders' representatives (near-parity representation). More recently, Kraft (1998) considered a tractable Cournot duopoly model on the strategic effect of employment bargaining in duopolistic interaction with homogenous products showing that profit maximising firms have an incentive to become bargainers over employment. Specifically, he showed that in a game played by firms that must choose between profit maximisation and codetermination, the latter results to be the dominant strategy. However, this Nash equilibrium strategy is Pareto inefficient, in line with the common wisdom that the presence of unions deciding on employment harms the firms' profitability. Then, Kraft (2001) extended his previous work by accounting for a general oligopolistic market and confirmed the existence of a prisoner's dilemma for a large range of the union's bargaining power. Other four contributions have extended the early literature. Three of

\footnotetext{
4 The Bertelsmann and Hans Böckler Foundations, whose work was reported in 1998, set up the special Codetermination Commission/Kommission Mitbestimmung in 1996.
} 
them introduced R\&D activities in a codetermined setting. Specifically, Granero $(2006)^{5}$ showed codetermination could help a firm to increase market share, employment and innovativity. Kraft et al. $(2011)^{6}$ found no support to conclude that codetermination negatively affects technological progress and innovativity. Fanti et al. (2018) ${ }^{7}$ revisited Kraft (1998) and Kraft et al. (2011) finding that their results may not be robust to a more general setting including horizontal product differentiation à la Singh and Vives (1984). Differently, Gürtler and Höffler (2015) started from the (stylised) fact that workers protection in the European Union is stronger than in the US (by stressing the role played by works councils in German codetermined large companies) ${ }^{8}$ and focused on the role of works councils on the monitoring of workers. ${ }^{9}$

On the strict side of empirical evidence, there exist little and controversial results. ${ }^{10}$ For instance, Frick (2001) - in a production function study using the 1998 wave of the IAB Establishment Panel - obtained a positive evidence on firms' performance. Specifically, he found that the existence of works council is associated with 25 (resp. 30) percent higher labour productivity in western (resp. eastern) Germany. However, according to Addison et al. (2004) that correlation may reflect omitted variables bias as well as an inadequate measure of capital (proxied by the log of replacement investment). This is because by using the same data set and applying first differences they were

\footnotetext{
5 The author built on a quantity setting duopoly by assuming that the objective function of the firm/manager is a weighted sum of profits and the income paid to workers, where the relative proportions of board votes of shareholders and workers represent the weight of the problem.

${ }^{6}$ By taking Kraft $(1998,2001)$ as a starting point, Kraft et al. (2011) studied the effects of the German Codetermination Act of 1976 - introducing the possibility of equal representation of employers and employees' representative on the supervisory board of large companies - on the innovative activity of German firms. The authors proposed a duopoly model by (exogenously) comparing profits and R\&D innovative activity under codetermination and profit maximisation by assuming that $R \& D$ was not the subject of negotiations.

7 First, the authors revisited the codetermined duopoly of Kraft (1998) by extending it with differentiated products. Then, they endogeneised the equilibrium firms' choices between profit maximisation codetermination in a Cournot duopoly game with R\&D activities.

8 "Within the system of "co-determination" works councils have legally guaranteed influence on management decisions concerning working conditions within a firm. For instance, the law prescribes that worker representatives must consent to any introduction of technologies that monitor the workers' effort and output." (Gürtler and Höffler, 2015, p. 1366).

9 Also, Fanti and Gori (2012) considered a Kraft-like economy, but mainly focusing on the stability effects of codetermination in a context of bounded rationality

10 As noted first by FitzRoy and Kraft (1993, p. 366) "there have been few attempts to quantify economic effects, and they all suffer from inadequate data and methodology" and then by Gorton and Schmid (2004, p. 867) "There is relatively little quantitative work on the effects of codetermination at the supervisory board level".
} 
unable to replicate such a result. ${ }^{11}$ Similarly, by considering a stochastic production frontier approach and a large panel data set, Schank et al. (2004) investigated whether works councils act as sand or grease in the operation of German firms. Their analysis suggested that establishments with and without a works council did not exhibit significant differences in efficiency, that is they fail to detect material differences in establishment efficiency by works council status. By also reviewing the other literature documenting the effects of codetermination on establishment or firm performance (i.e., amongst others, FitzRoy and Kraft (1987) and Addison et al. (1993) with regard to the evidence on total factor productivity, FitzRoy and Kraft (1985), Addison et al. (1993) and Addison et al. (1997) on firm profitability, Addison et al. (1993) studied also the effects of codetermination on the investment in physical capital, FitzRoy and Kraft (1990), Schnabel and Wagner (1994), and Addison et al. (1997) analysed how codetermination affects investments in intangible capital, Gorton and Schmid (2004) with regard to the evidence on the market value of firms), we may argue that it is difficult to find contributions that support codetermination. This is because most of these studies pinpointed to it adversely affect performances or, at best, there exist statistically insignificant economic effects. Addison et al. (2004) also provided new information on the extent of works councils after the reform of 2001. They investigated the effects of works council formation on labour productivity, financial performance and employment development, and focusing on some new results from matched-plant data by showing that the absence of codetermination did not appear to have negative consequences for workplace productivity, profitability, and employment.

We pinpoint that another stylised of actual (modern) economies is represented by the existence of several products for which the utility drawn by a single consumer increases with the number users, i.e. the total sales of the goods increase the welfare of each consumer (e.g., Katz and Shapiro,

\footnotetext{
${ }^{11}$ For the sake of precision, other authors have empirically provided some positive association between codetermination and firm performances. For instance, Cable and FitzRoy (1980) found positive effects of codetermination on labour productivity and FitzRoy and Kraft (2005) concluded for a positive labour productivity effect of near parity codetermination.
} 
1985). These goods are characterised by a positive consumption externality and are called network goods. Examples of network goods include software, computers, consumer electronics, telephones and other communication services (e.g., Shy, 2001). More in general, positive network externalities may exist for products that a consumer wants to get because others do (i.e. the so-called Bandwagon Effect). Moreover, a consumer/user's demand for a network good may positively depend on the number of other consumers/users of it through other ways. This is the case when customers perceive a product as a signal of the availability of after-sale services for long-lasting consumers or product quality. ${ }^{12}$ For instance, in the market of mobile telecommunications there are several possible sources of network effects, which can be resumed as follows (Baraldi, 2012). 1) When there is a rising number of users having subscribed to a network, it becomes more attracting for others buying a mobile phone and subscribing to the same network. 2) The network expansion drives the usage volume of people already using mobile telecommunication. Then, the usage volume of existing subscribers is expected to increase with the total number of mobile telephone subscribers. 3) By considering the recent approach of the social interaction theory (e.g. Schoder, 2000), another source of network externality is a need of people to buy, consume and behave as their follows. Therefore, we expect a network effect driven by such conformist behaviour.

Recently, it has been shown that several established results belonging to the Industrial Organisation literature may change when the effects of network goods industries are investigated. For instance, this hols in an oligopoly context with network externalities in consumption. In particular, 1) Hoernig (2012), Bhattacharjee and Pal (2014), and Chirco and Scrimitore (2013) showed that the established results of the oligopoly managerial delegation literature may not hold, 2) Fanti and Buccella $(2017,2018)$ found that the common wisdom regarding the bargaining agenda (between unions and firms) and corporate social responsibility may change, 3) Song and Wang (2017) showed that when strength of the network effect of strong enough, collusion becomes more

\footnotetext{
${ }^{12}$ In fact, we may include in the category of network goods most consumer durable goods to the extent that utility of consumer durables is positively linked with the quality of post-sales services and higher consumer-base is positively linked with better post-sales services.
} 
sustainable when products are close substitutes. This contrasts with the conventional wisdom that collusion between firms will be destabilised when the degree of product substitutability is large.

Empirical evidence of important network effects also for industries located in countries with the institution of codetermination (e.g., Germany) does exist. For example, by focusing again on the case of telecommunications, Doganoglu and Grzybowski (2007) studied network effects in the German mobile telecommunications market. They estimated a system of demand functions for mobile subscribers in Germany (data on mobile subscriptions was collected from the Internet site run by the German regulator - RegTP) from January 1998 to June 2003 finding that network effects played a significant role in the diffusion of mobile services in Germany. They concluded that if the previous period total installed base increased by $1 \%$, current period sales would surge on average by 0.69\%. ${ }^{13}$ Baraldi (2012) analyses 30 OECD Countries from 1989 to 2006, by specifying and estimating a model of consumer demand for mobile telephone calls aimed at identifying the extent of network externalities. The author showed (Table 7, p. 19) that also for countries such as Austria and Germany the network effect is large (though less than the one found by Doganoglu and Grzybowski, 2007). This confirms that the competition analysis under codetermination in industries producing network goods (such as the telecommunications sector) should consider for the existence and intensity of network effects. Therefore, the consumers' expectations about the total sales of the goods may be in principle affected by different labour market institutions. However, we note that the theoretical literature above mentioned has only considered Cournot competition. Differently, in several markets, firms compete on prices (e.g., internet service providers, financial services and so on). Firms might also have an incentive to differentiate their products specially to avoid losing the customers' demand when their prices are larger than those of the rivals are. ${ }^{14}$ Against this backdrop,

\footnotetext{
${ }^{13}$ As they note, "If there were no network effects, the penetration of mobiles at the end of the period analyzed could be at least $50 \%$ lower."

${ }^{14}$ As is known, the theoretical literature has attempted to identify when and how firms could compete on prices rather on quantities (e.g. Kreps and Scheinkman, 1983). In a nutshell, i) quantity competition seems more natural when firms must make production decisions in advance and are committed to selling all of their output, because, for instance, of sunk production costs or too much costly inventories, ii) price competition is more appropriate when capacity is sufficiently flexible that firms can always satisfy all of the demand that arises at the prices they announce. For instance,
} 
this article aims at revisiting the theoretical literature on codetermination led by Cournot setting by considering the alternative mode of product market competition, i.e. price competition, and accounting for network goods. By developing a Bertrand's model with differentiated products this article shows, in sharp contrast with the previous literature, that codetermination does never emerge as a Nash equilibrium in a price-setting non-network setting. Then, by considering a network market, it pinpoints how codetermination can indeed become a sub-game perfect Nash equilibrium when prices are strategic substitutes or strategic complements. More interestingly, this equilibrium may be Pareto efficient.

The rest of the article proceeds as follows. Section 2 sets up a network-codetermination game with price competition by also presenting and discussing the main result of the work. Section 3 outlines the conclusions.

\section{The network-codetermination game with price competition}

This section begins with by detailing the main features of a network-codetermination game with price competition. The production side of the economy is comprised of two firms (duopoly) each of which produces a commodity perceived by customers as horizontally differentiated from the commodity produced by the rival (Singh and Vives, 1984). The technology used by firm $i=\{1,2\}$ to produce goods of variety $i$ employs a production function with constant returns to labour, so that $q_{i}=L_{i}$, where $L_{i}$ is the labour force hired by the firm and $q_{i}$ is the quantity sold in the output market. Each firm faces a constant marginal (and average) cost $0 \leq w<1$ (Correa-López and Naylor, 2004) representing the wage per unit of labour set in a centralised or industry-wide bargaining, which is taken as given by each single firm in the network industry (Kraft, 1998; Fanti

the airline industry is typically considered as illustrative of the fact that competition resembles either Bertrand's model or Cournot's model depending on the business cycle. In the network industries price competition seems to be at least as plausible as quantity competition. 
et al., 2018). Therefore, firm $i$ 's profits are expressed as follows $\Pi_{i}=\left(p_{i}-w\right) q_{i}$, where $p_{i} \geq 0$ is firm $i$ 's price.

There exists a continuum of identical consumers with preferences represented by a separable utility function $V\left(q_{1}, q_{2}, y_{1}, y_{2}, m\right)$, which is linear in the numeraire good $m$ (produced in a competitive sector). The representative consumer maximises $V\left(q_{1}, q_{2}, y_{1}, y_{2}, m\right)=U\left(q_{1}, q_{2}, y_{1}, y_{2}\right)+m$ subject to the budget constraint $p_{1} q_{1}+p_{2} q_{2}+m=R$, where $U\left(q_{1}, q_{2}, y_{1}, y_{2}\right)$ is a twice continuously differentiable function, $q_{1}$ and $q_{2}$ are the control variables of the problem and $R$ is the consumer's exogenous nominal income. This income is high enough to avoid the existence of corner solutions. Different from the traditional industrial organisation literature, we assume the existence of network externalities in consumption. This implies that one person's demand also depends on the demand of other consumers. The simple mechanism of network effects we are accounting for in this work follows the tradition initiated by Katz and Shapiro (1985). The issue of network externalities has become relevant especially due to the tremendous growth of the internet-related activities (e.g., online games, telephone and so on) in markets where firms are price setters.

By following the spirit of several recent works dealing with network effects in a strategic competitive framework (Hoernig, 2012; Bhattacharjee and Pal, 2013; Chirco and Scrimitore, 2013; Pal, 2014, 2015; Song and Wang 2017), we assume that consumers' preferences are represented by the following utility function:

$$
U\left(q_{i}, q_{j}, y_{i}, y_{j}\right)=q_{i}+q_{j}-\frac{1}{2}\left(q_{i}^{2}+q_{j}^{2}+2 d q_{i} q_{j}\right)+n\left[q_{i}\left(y_{i}+d y_{j}\right)+q_{j}\left(y_{j}+d y_{i}\right)\right]-\frac{n}{2}\left(y_{i}^{2}+y_{j}^{2}+2 d y_{i} y_{j}\right),(1)
$$

where $i, j=\{1,2\}(i \neq j), y_{i}$ denotes consumers' expectations about firm $i$ 's equilibrium total sales and represents a consumption externality, $0 \leq n<1$ is the strength of the (positive) externality ( $n=0$ is the standard non-network industry), and $-1 \leq d \leq 1$ is a parameter capturing the degree of product differentiation as perceived by customers. When $d=1$ (resp. $d=-1$ ) products are perfect substitutes (resp. perfect complements), whereas $0<d<1$ (resp. $-1<d<0$ ) reflects the case of 
imperfect substitutability (resp. imperfect complementarity). The case $d=0$ implies that each firm behaves as if it were a monopolist for its own product. We note that the last addendum in (1) is a specific symmetric function of expectations such that for each given consumption vector $\left(q_{1}, q_{2}\right)$ utility is highest if expectations are correct.

The utility function in (1) is a modified version of the one used by Singh and Vives (1984). The reason why adopting this version here is simple. The utility function popularised by Hoernig (2012) is not defined for the case of homogeneous goods. Although we do not include the case of perfect substitutability here to avoid the model falls within the standard Bertrand paradox, we preferred employing the version expressed in (1) to overcome this lacuna. By solving the utility maximisation programme gives the following linear inverse demand of product of variety $i$ :

$$
p_{i}=1-q_{i}-d q_{j}+n\left(y_{i}+d y_{j}\right), \quad i, j=\{1,2\}, i \neq j
$$

From (2), it is easy to see that network externalities enter additively in the demand function. An increase in the strength of network effects $(n \uparrow)$ causes an outward shift in the demand curve that in turn implies an increase in the quantity bought by consumers for any given value of the price. This externality therefore acts as a device that increases the market size. As in the present model firms compete on prices, we need to employ the direct demand version of (2), which is obtained by inverting the direct demand of firm $i$ and using the corresponding counterpart version of firm $j$. This is given by the following expression:

$$
q_{i}=\frac{1-p_{i}-d\left(1-p_{j}\right)}{1-d^{2}}+n y_{i}, \quad i, j=\{1,2\}, i \neq j
$$

By following the literature led by Kraft (1998), and recently revisited by Fanti et al. (2018), we assume the existence of the institution of codetermination. Therefore, firms' representatives bargain with employees' representatives over employment but not over wages on the supervisory board. By translating this concept in a price setting duopoly industry, we should have that the objective of firm 
$i$ is to maximise its own profits $\Pi_{i}$ with respect to $p_{i}$. By using the inverse demand Eq. (3), profits are the following:

$$
\Pi_{i}=\left(p_{i}-w\right)\left[\frac{1-p_{i}-d\left(1-p_{j}\right)}{1-d^{2}}+n y_{i}\right]
$$

Differently, each firm-specific union aims at maximising its own utility $Z_{i}=\left(w_{i}-w^{\circ}\right) L_{i}$ with respect to $p_{i}$ by knowing that $L_{i}=q_{i}$ and using the quantity dictated by the direct demand in (3), where $w^{\circ}$ is the reservation (or competitive) wage, which is set to zero without loss of generality, henceforth. Therefore, the utility function of the union bargain unit of firm $i$ simplifies as follows:

$$
Z_{i}=w\left[\frac{1-p_{i}-d\left(1-p_{j}\right)}{1-d^{2}}+n y_{i}\right]
$$

The Nash bargaining over prices between each firm and union bargain unit takes the form:

$$
\mathrm{N}_{i}=\Pi_{i}^{\beta} Z_{i}^{1-\beta}=\left\{\left(p_{i}-w\right)\left[\frac{1-p_{i}-d\left(1-p_{j}\right)}{1-d^{2}}+n y_{i}\right]\right\}^{\beta}\left\{w\left[\frac{1-p_{i}-d\left(1-p_{j}\right)}{1-d^{2}}+n y_{i}\right]\right\}^{1-\beta},
$$

where $p_{i}$ is the control variable, $y_{i}$ is taken as given (representing the positive externality induced by consuming goods in a network industry) and $0<\beta \leq 1$ is the relative bargaining power of firm $i$. By following Kraft (1998) and the literature cited therein, the threat points have been set to zero.

The timing of the events of this two-stage game is the following. At the codetermination stage (stage 1), each owner must choose to be either a codetermined or profit maximisation firm. At the bargaining market stage (stage 2), firms either choose the price in the output market in the case of profit maximisation or bargain together with unions in the case of codetermination in a network industry. As is usual from Katz and Shapiro (1985) and Hoernig (2012), consumers have rational expectations. Therefore, at the second stage of the game we impose that $q_{1}=y_{1}$ and $q_{2}=y_{2}$ hold in equilibrium. We proceed into the analysis according to the standard backward logic. 
Codetermination. First, we consider that both firms are codetermined $(\beta<1)$ so that the price should be set for product of variety $i$ at the second stage of the game is chosen by firms and employees' representatives by maximising the expression in (6) with respect to $p_{i}$. Therefore, the reaction function of the $i$ th firm is given by:

$$
\frac{\partial \mathrm{N}_{i}}{\partial p_{i}}=0 \Leftrightarrow p_{i}\left(p_{j}, y_{i}, y_{j}\right)=\frac{w+\beta\left[1-d+d p_{j}+\left(1-d^{2}\right) n y_{i}\right]}{1+\beta}
$$

From (7), an increase in the strength of the network externality shifts upward the reaction function of firm $i$ and then causes an increase in the price consumers are willing to pay for any given value of the quantity produced by the firm. We note that when products are substitutes $(0<d<1)$ the reaction functions of both firms (whose behaviour is symmetric in this case) are upward sloping and prices are strategic complements. Differently, when products are complements $(-1<d<0)$ the reaction functions of both firms are downward sloping and prices are strategic substitutes. By using (7) together with the corresponding counterpart of firm $j$ and knowing that $y_{i}=q_{i}$ and $y_{j}=q_{j}$, $i, j=\{1,2\}(i \neq j)$, we definitely get the equilibrium outcome of firm $i$, that is:

$$
p_{i}^{B / B}=\frac{\beta(1-d)+w(1-n)}{1-n+\beta(1-d)},
$$

where the superscript B denotes "bargaining" under codetermination. Therefore, equilibrium quantity and profit of firm $i$ are respectively given by:

$$
q_{i}^{B / B}=\frac{1-w}{(1+d)[1-n+\beta(1-d)]},
$$

and

$$
\Pi_{i}^{B / B}=\frac{\beta(1-w)^{2}(1-d)}{(1+d)[1-n+\beta(1-d)]^{2}} .
$$

Straightforward algebra from (8), (9) and (10) show that an increase in $n$ causes a monotonic increase in the price consumers are willing to pay for any given value of the quantity of products of variety $i$ and variety $j$, the quantity produced by both firms and their own profits. 
Profit maximisation. If both firms are profit maximisers $(\beta=1)$, the equilibrium value of price, output and profit of firm $i$ are the following:

$$
\begin{gathered}
p_{i}^{P M / P M}=\frac{1-d+w(1-n)}{2-n-d}, \\
q_{i}^{P M / P M}=\frac{1-w}{(1+d)(2-n-d)},
\end{gathered}
$$

and

$$
\Pi_{i}^{P M / P M}=\frac{(1-w)^{2}(1-d)}{(1+d)(2-n-d)^{2}},
$$

where the superscript PM denotes "profit maximisation".

Asymmetric behaviour. Let us now consider the asymmetric case in which firm 1 is codetermined and firm 2 is a profit maximiser. Therefore, at the bargaining market stage, firm 1 and its corresponding union bargain unit are involved in a bargaining aimed at maximising $\mathrm{N}_{1}$ with respect to $p_{1}$, whereas firm 2 maximises $\Pi_{2}$ with respect to $p_{2}$. The reaction functions are given by:

$$
\frac{\partial \mathrm{N}_{1}}{\partial p_{1}}=0 \Leftrightarrow p_{1}\left(p_{2}, y_{1}, y_{2}\right)=\frac{w+\beta\left[1-d+d p_{2}+\left(1-d^{2}\right) n y_{1}\right]}{1+\beta}
$$

and

$$
\frac{\partial \Pi_{2}}{\partial p_{2}}=0 \Leftrightarrow p_{2}\left(p_{1}, y_{1}, y_{2}\right)=\frac{w+1-d+d p_{1}+\left(1-d^{2}\right) n y_{2}}{2}
$$

By imposing the conditions $y_{1}=q_{1}$ and $y_{2}=q_{2}$, we easily get:

$$
p_{1}^{B / P M}=\frac{w(1-n)(2-n+\beta d)+\beta[2-n-d(1-n+d)]}{(1-n)(2-n)+\beta\left(2-n-d^{2}\right)},
$$

and

$$
p_{2}^{B / P M}=\frac{w(1-n)(1-n+d+\beta)+(1-n)(1-d)+\beta\left(1-d^{2}\right)}{(1-n)(2-n)+\beta\left(2-n-d^{2}\right)} .
$$


Therefore, the equilibrium values of the quantity produced by firm 1 and firm 2 and their own corresponding profits are the following:

$$
\begin{aligned}
& q_{1}^{B / P M}=\frac{(1-w)(2-n+d)}{(1+d)\left[(1-n)(2-n)+\beta\left(2-n-d^{2}\right)\right]}, \\
& q_{2}^{B / P M}=\frac{(1-w)[1-n+\beta(1+d)]}{(1+d)\left[(1-n)(2-n)+\beta\left(2-n-d^{2}\right)\right]},
\end{aligned}
$$

and

$$
\begin{aligned}
& \Pi_{1}^{B / P M}=\frac{\beta(1-w)^{2}(1-d)(2-n+d)^{2}}{(1+d)\left[(1-n)(2-n)+\beta\left(2-n-d^{2}\right)\right]^{2}}, \\
& \Pi_{2}^{B / P M}=\frac{(1-w)^{2}(1-d)[1-n+\beta(1+d)]^{2}}{(1+d)\left[(1-n)(2-n)+\beta\left(2-n-d^{2}\right)\right]^{2}} .
\end{aligned}
$$

The equilibrium outcomes of this game are summarised in Table 1 (price), Table 2 (quantity) and Table 3 (profit) according to the strategies available to each player.

\begin{tabular}{|l|l|l|}
\hline Firm 1 & PM & $\mathrm{B}$ \\
\hline PM & $\frac{1-d+w(1-n)}{2-n-d}, \frac{1-d+w(1-n)}{2-n-d}$ & $\frac{w(1-n)(1-n+d+\beta)+(1-n)(1-d)+\beta\left(1-d^{2}\right)}{(1-n)(2-n)+\beta\left(2-n-d^{2}\right)}$ \\
\hline $\mathrm{B}$ & $\frac{\frac{w(1-n)(2-n+\beta d)+\beta[2-n-d(1-n+d)]}{(1-n)(2-n+\beta d)+\beta[2-n-d(1-n+d)]}}{(1-n)(2-n)+\beta\left(2-n-d^{2}\right)}$, & $\frac{\beta(1-d)+w(1-n)}{1-n+\beta(1-d)}, \frac{\beta(1-d)+w(1-n)}{1-n+\beta(1-d)}$ \\
& $\frac{w(1-n)(1-n+d+\beta)+(1-n)(1-d)+\beta\left(1-d^{2}\right)}{(1-n)(2-n)+\beta\left(2-n-d^{2}\right)}$ & \\
\hline
\end{tabular}

Table 1. Equilibrium values of prices under B and PM.

\begin{tabular}{|l|l|l|}
\hline Firm 1 & PM & B \\
\hline PM & $\frac{1-w}{(1+d)(2-n-d)}, \frac{1-w}{(1+d)(2-n-d)}$ & $\frac{(1-w)[1-n+\beta(1+d)]}{(1+d)\left[(1-n)(2-n)+\beta\left(2-n-d^{2}\right)\right]}$, \\
& $\frac{(1-w)(2-n+d)}{(1+d)\left[(1-n)(2-n)+\beta\left(2-n-d^{2}\right)\right]}$ \\
\hline
\end{tabular}




\begin{tabular}{|l|c|c|}
\hline $\mathrm{B}$ & $\frac{(1-w)(2-n+d)}{(1+d)\left[(1-n)(2-n)+\beta\left(2-n-d^{2}\right)\right]}$, & $\frac{1-w}{(1+d)[1-n+\beta(1-d)]}, \frac{1-w}{(1+d)[1-n+\beta(1-d)]}$ \\
& $\frac{(1-w)[1-n+\beta(1+d)]}{(1+d)\left[(1-n)(2-n)+\beta\left(2-n-d^{2}\right)\right]}$ & \\
\hline
\end{tabular}

Table 2. Equilibrium values of quantities under B and PM.

\begin{tabular}{|l|l|l|}
\hline Firm 1 & PM & B \\
\hline PM & $\frac{(1-w)^{2}(1-d)}{(1+d)(2-n-d)^{2}}, \frac{(1-w)^{2}(1-d)}{(1+d)(2-n-d)^{2}}$ & $\frac{(1-w)^{2}(1-d)[1-n+\beta(1+d)]^{2}}{(1+d)\left[(1-n)(2-n)+\beta\left(2-n-d^{2}\right)\right]^{2}}$, \\
\hline B & $\frac{\beta(1-w)^{2}(1-d)(2-n+d)^{2}}{(1+d)\left[(1-n)(2-n)+\beta\left(2-n-d^{2}\right)\right]^{2}}$, & $\frac{\beta(1-w)^{2}(1-d)(2-n+d)^{2}}{(1+d)\left[(1-n)(2-n)+\beta\left(2-n-d^{2}\right)\right]^{2}}$ \\
& $\frac{(1-w)^{2}(1-d)[1-n+\beta(1+d)]^{2}}{(1+d)\left[(1-n)(2-n)+\beta\left(2-n-d^{2}\right)\right]^{2}}$ & \\
\hline
\end{tabular}

Table 3. Payoff matrix (profits) under B and PM (homogeneous products).

Let

$$
\begin{aligned}
& d_{a}(\beta, n):=\frac{\sqrt{\beta(2-n)[\beta-(1-n) \sqrt{\beta}]}}{\beta}, \\
& d_{b}(\beta, n):=\frac{\sqrt{(1-n+\beta)[\beta-(1-n) \sqrt{\beta}]}}{\beta}
\end{aligned}
$$

and

$$
d_{c}(\beta, n):=1-\frac{1-n}{\sqrt{\beta}}
$$

be three threshold values of the degree of product differentiation such that the profit differentials

$$
\begin{aligned}
& \Delta_{a}=\Pi_{i}^{B / P M}-\Pi_{i}^{P M / P M}=0, \quad \Delta_{b}=\Pi_{i}^{P M / B}-\Pi_{i}^{B / B}=0 \quad \text { and } \quad \Delta_{c}=\Pi_{i}^{P M / P M}-\Pi_{i}^{B / B}=0, \quad \text { respectively } \\
& (i, j=\{1,2\}, i \neq j) \text {. Let }
\end{aligned}
$$

$$
\beta_{T}:=(1-n)^{2}
$$

be a threshold value of the bargaining power (obtained as a solution for $\beta$ of $\left.d_{a}(\beta, n)=d_{b}(\beta, n)=d_{c}(\beta, n)=0\right)$. We note that $d_{a}(\beta, n)$ and $d_{b}(\beta, n)$ are binding if and only if $\beta>\beta_{T}$ 
for any $0 \leq n<1$, otherwise they do not apply for meaningful values of both the relative bargaining power of the firm and degree of product differentiation. The shape of $d_{a}(\beta, n)$ (solid line), $d_{b}(\beta, n)$ (dashed line) and $d_{c}(\beta, n)$ (dotted line) is depicted in Panels (a)-(d) of Figure 1 in the parameter space $(\beta, d)$ for different values of the network parameter $n$. These values are the following: $n=0$ (no network effects, Panel (a)), $n=0.3$ (Panel (b)), $n=0.5$ (Panel (c)) and $n=0.7$ (Panel (d)). As is clear by looking at the figure, the smaller (resp. larger) the value of the network externality, the smaller (resp. larger) the parameter space $(\beta, d)$ in which the thresholds $d_{a}(\beta, n)$ and $d_{b}(\beta, n)$ apply. In the limiting case of no network effects, these thresholds are never meaningful for any $0<\beta \leq 1$ and $-1<d<1$. The red point on the $\beta$-axis in the different panels of Figure 1 represent the threshold $\beta_{T}$ and may help clarifying the working of the network externality in determining the outcomes of the game at the codetermination stage (stage 1), where each owner has to choose to be either a codetermined or profit maximising firm in a price-setting network industry. Indeed, the vertical solid red line starting from the red point separates the area in which codetermination does not emerge from the area in which it can emerge as a market outcome depending on the relative size of $\beta$ and $d$. To this purpose, Propositions 1,2 and 3, and Corollary 1 show the different spectrum of equilibrium outcomes of this two-stage game and highlight the important role of the strength of the network externality in letting codetermination emerging as a Nash equilibrium.

Proposition 1. Let $\beta<\beta_{T}$ hold. [Product substitutability]. (1) If $1>d>0$ then (PM,PM) is the unique Pareto efficient SPNE of the game (cooperation game). [Product complementarity]. (2) If $0>d>-d_{c}(\beta, n)$ then $(\mathrm{PM}, \mathrm{PM})$ is the unique Pareto efficient SPNE of the game (cooperation game). (3) If $-d_{c}(\beta, n)>d>-1$ then (PM,PM) is the unique Pareto inefficient SPNE of the game (prisoner's dilemma). 
Proposition 2. Let $\beta>\beta_{T}$ hold. [Product substitutability]. (1) If $1>d>d_{b}(\beta, n)$ then (PM,PM) is the unique Pareto efficient SPNE of the game (cooperation game). (2) If $d_{b}(\beta, n)>d>d_{a}(\beta, n)$ then there exist two pure-strategy Nash equilibria given by $(\mathrm{B}, \mathrm{B})$ and $(\mathrm{PM}, \mathrm{PM})$, and $\mathrm{PM}$ payoff dominates $\mathrm{B}$ (coordination game). (3) If $d_{a}(\beta, n)>d>d_{c}(\beta, n)$ then $(\mathrm{B}, \mathrm{B})$ is the unique Pareto inefficient SPNE of the game (prisoner's dilemma). (4) If $d_{c}(\beta, n)>d>0$ then $(\mathrm{B}, \mathrm{B})$ is the unique Pareto efficient SPNE of the game (cooperation game). [Product complementarity]. (5) If $0>d>-d_{a}(\beta, n)$ then $(\mathrm{B}, \mathrm{B})$ is the unique Pareto efficient SPNE of the game (cooperation game). (6) If $-d_{a}(\beta, n)>d>-d_{b}(\beta, n)$ then there exist two pure-strategy Nash equilibria given by (B,B) and (PM,PM), and B payoff dominates PM (coordination game). (7) If $-d_{b}(\beta, n)>d>-1$ then (PM,PM) is the unique Pareto inefficient SPNE of the game (prisoner's dilemma).

Corollary 1. If $n=0$ (no network effects) then $(\mathrm{B}, \mathrm{B})$ does never emerge as a Nash equilibrium of the game.

Proof. The profit differentials $\Delta_{a}, \Delta_{b}$ and $\Delta_{c}$ are the following:

$$
\begin{aligned}
& \Delta_{a}=\frac{(1-w)^{2}(1-d)(1-\beta)\left[\beta d^{4}-2 \beta(2-n) d^{2}-n^{4}+6 n^{3}-(13-\beta) n^{2}+4(3-\beta) n-4(1-\beta)\right]}{(1+d)(2-n-d)^{2}\left[(1-n)(2-n)+\beta\left(2-n-d^{2}\right)\right]^{2}}, \\
& \Delta_{b}=\frac{(1-w)^{2}(1-d)(1-\beta)}{(1+d)[1-n+\beta(1-d)]^{2}\left[(1-n)(2-n)+\beta\left(2-n-d^{2}\right)\right]^{2}} \times \\
& \times\left[-\beta^{3} d^{4}+2 \beta^{2}(1+\beta-n) d^{2}+\beta n^{2}(5+\beta-2 n)+(1+\beta)\left(1-\beta^{2}\right)-n^{3}(4-n)+6 n^{2}-4 n(1+\beta)\right]
\end{aligned},
$$

and

$$
\Delta_{c}=\frac{(1-w)^{2}(1-d)(1-\beta)\left[(1-n)^{2}-\beta+\beta d(2-d)\right]}{(1+d)(2-n-d)^{2}[1-n+\beta(1-d)]^{2}} .
$$

The sign of $\Delta_{a}, \Delta_{b}$ and $\Delta_{c}$ change depending on the relative size of $d, \beta$ and $n$. Let us consider first the case $\beta<\beta_{T}$. (1) If $1>d>0$ then $\Delta_{a}<0, \Delta_{b}>0$ and $\Delta_{c}>0$. (2) If $0>d>-d_{c}(\beta, n)$ then $\Delta_{a}<0, \Delta_{b}>0$ and $\Delta_{c}>0$. (3) If $-d_{c}(\beta, n)>d>-1$ then $\Delta_{a}<0, \Delta_{b}>0$ and $\Delta_{c}<0$. Therefore, 
Proposition 1 follows. Let us consider now the case $\beta>\beta_{T}$. (1) If $1>d>d_{b}(\beta, n)$ then $\Delta_{a}<0, \Delta_{b}>0$ and $\Delta_{c}>0$. (2) $d_{b}(\beta, n)>d>d_{a}(\beta, n)$ then $\Delta_{a}<0, \Delta_{b}<0$ and $\Delta_{c}>0$. (3) If $d_{a}(\beta, n)>d>d_{c}(\beta, n)$ then $\Delta_{a}>0, \Delta_{b}<0$ and $\Delta_{c}>0$. (4) If $d_{c}(\beta, n)>d>0$ then $\Delta_{a}>0, \Delta_{b}<0$ and $\Delta_{c}<0$. (5) If $0>d>-d_{a}(\beta, n)$ then $\Delta_{a}>0, \Delta_{b}<0$ and $\Delta_{c}<0$. (6) If $-d_{a}(\beta, n)>d>-d_{b}(\beta, n)$ then $\Delta_{a}<0, \Delta_{b}<0$ and $\Delta_{c}<0$. (7) If $-d_{b}(\beta, n)>d>-1$ then $\Delta_{a}<0, \Delta_{b}>0$ and $\Delta_{c}<0$. Therefore, Proposition 2 follows. If $n=0$ then $\beta_{T}=1$ and $\beta \leq \beta_{T}$ holds for $0<\beta \leq 1$. Therefore, depending on the relative size of $d$, the outcome of the game is given by one of the points of Proposition 1 and Corollary 1 holds. Q.E.D.

Proposition 3. An increase in $n$ monotonically reduces the threshold value $\beta_{T}$. An increase in $\beta$ (or in $n$ ) monotonically increases the threshold values $d_{a}(\beta, n)$ and $d_{b}(\beta, n)$ such that $\Delta_{a}=0$ and $\Delta_{b}=0$, respectively, for any $\beta_{T}<\beta \leq 1$ and $0<n<1$. An increase in $\beta$ (or in $n$ ) monotonically increases the threshold value $d_{c}(\beta, n)$ such that $\Delta_{c}=0$ for any $0<\beta \leq 1$ and $0<n<1$.

Proof. The proof easily follows by looking at the sign of first order derivatives of the different thresholds with respect to $\beta$ and $n$. Q.E.D.

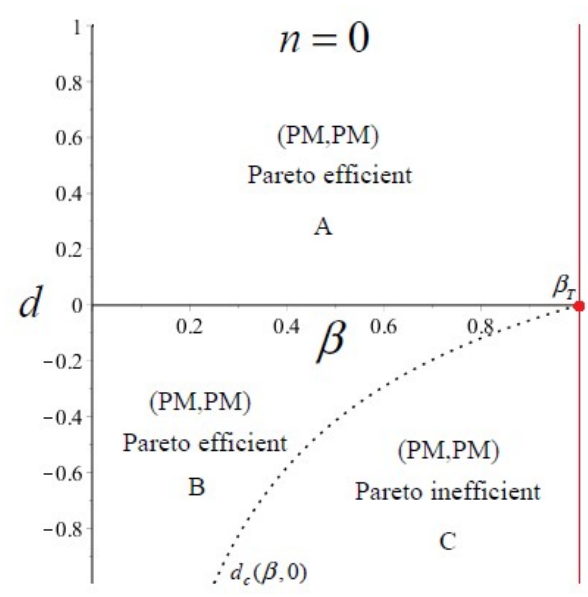

(a)



(b) 


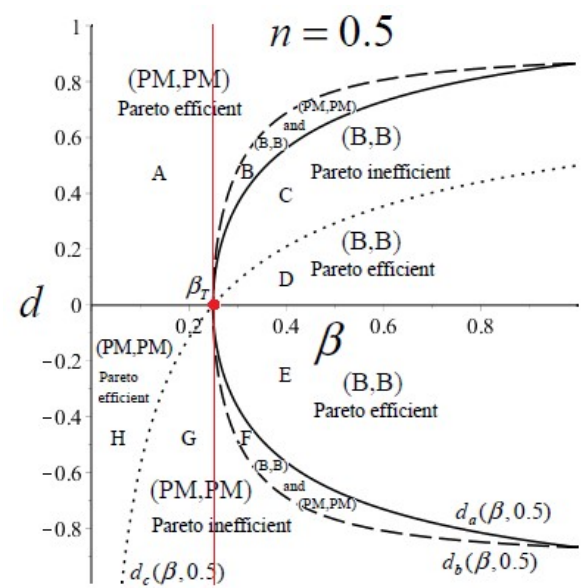

(c)

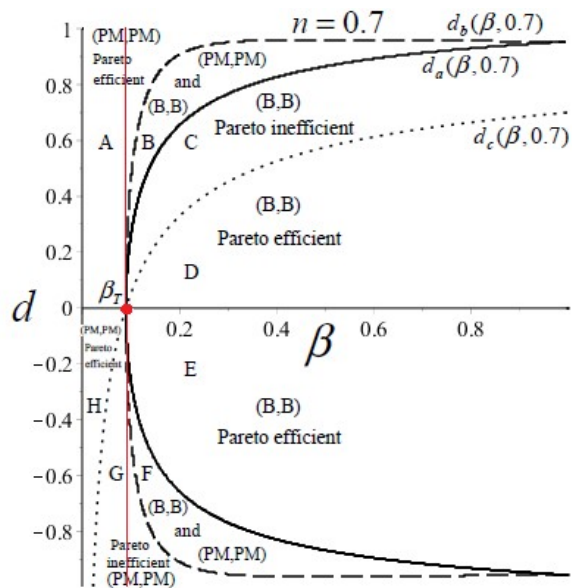

(d)

Figure 1. Codetermination and network externalities in a price-setting duopoly. Nash equilibrium outcomes in $(\beta, d)$ plane for different values of $n$. The solid (resp. dashed) [resp. dotted] line represents the threshold value $d_{a}(\beta, n)$ (resp. $\left.d_{b}(\beta, n)\right)$ [resp. $d_{c}(\beta, n)$ ] related to $\Delta_{a}=0$ (resp. $\left.\Delta_{b}=0\right)$ [resp. $\Delta_{c}=0$ ]. Panel (a): $n=0$. Panel (b): $n=0.3$. Panel (c): $n=0.5$. Panel (d): $n=0.7$.

Given the critical role of $n$ in determining the emergence of codetermination as a Nash equilibrium outcome in a price-setting duopoly, the economic intuition behind these results is detailed below by dividing for the cases of non-network and network industries.

Non-network industry $(n=0)$. In the absence of network externalities, an increase in the bargaining power of unions $(\beta \downarrow)$ reduces, ceteris paribus, the price that consumers are willing to pay in the output market in the case both firms are codetermined and contributes to increase the quantity produced and sold by these firms. This also holds for the firm that is playing B in the case of asymmetric behaviours, whereas the firm that is playing PM experiences a reduction in both the price and quantity when $\beta$ is reducing. Therefore, the profits of the firm that is playing PM when the rival is playing B monotonically reduces when its firm-specific union becomes more aggressive in the bargaining to choose the price, i.e. when $\beta$ goes down. In all other cases, the positive effect on profits due to the expected increase in the quantity produced and sold in the market is never enough to offset the negative effect due to the corresponding reduction in the marginal willingness 
to pay of consumers due to a fiercer competition. This implies that profits are reducing when $\beta$ reduces in the case both firms are codetermined as well as in the case of asymmetric behaviour. However, the reduction in firms' profits under asymmetric behaviour is never sufficient to let the firm that is playing PM to deviate towards $\mathrm{B}$, that is $\mathrm{PM}$ is a dominant strategy for any $0<\beta \leq 1$ (we recall that if $n=0$ then $\beta_{T}=1$ and the thresholds $d_{a}(\beta, n)$ and $d_{b}(\beta, n)$ do never apply) and the Nash equilibrium (PM,PM) is Pareto efficient. This result is shown by comparing the examples reported in Table 4 and Table 5 representing the equilibrium outcomes (payoff matrix) of an increase in the bargaining power of the union in a non-network industry.

However, from a cooperation game (whose Nash equilibrium is Pareto efficient) firms can be entrapped in a prisoner's dilemma (whose Nash equilibrium is Pareto inefficient) if products of variety 1 and variety 2 become sufficiently complementary. This is because (for a given value of $\beta$ ) an increase in the degree of complementarity causes a profit increase in both cases PM and B. However, profits under B increase more than profits under PM (this is because the production of a codetermined firm is larger than the production of a profit maximising firm). Therefore, firms have an incentive to coordinate to play B, but no one has a unilateral to deviate from PM. This is because the firm that is playing PM when the other is playing B does not experience a sufficiently large profit increase to deviate towards B if products tend to become sufficiently complementary. This result is shown by comparing the examples reported in Table 5 and Table 6 for a given value of the bargaining power $(\beta=0.5)$ and represent the equilibrium outcomes (payoff matrix) of a nonnetwork industry when products are substitutes (Table 5), so that prices are strategic complements, and when products are complements (Table 6), so that prices are strategic substitutes.

\begin{tabular}{|l|l|l|}
\hline \multicolumn{1}{|l|}{ Firm 2 } & PM & B \\
Firm 1 & & \\
\hline PM & $0.148,0.148$ & $0.139,0.144$ \\
\hline B & $0.144,0.139$ & $0.136,0.136$ \\
\hline
\end{tabular}


Table 4. Payoff matrix (profits) under $\mathrm{B}$ and $\mathrm{PM}$ when $w=0, n=0, d=0.5$ and $\beta=0.8$. Cooperation game: (PM,PM) is the unique Pareto efficient SPNE of the game $\left(\Delta_{a}<0, \Delta_{b}>0\right.$ and $\left.\Delta_{c}>0\right)$.

\begin{tabular}{|l|l|l|}
\hline \multicolumn{1}{|c|}{ Firm 2 } & PM & B \\
Firm 1 & & \\
\hline PM & $0.148,0.148$ & $0.123,0.126$ \\
\hline B & $0.126,0.123$ & $0.106,0.106$ \\
\hline
\end{tabular}

Table 5. Payoff matrix (profits) under $\mathrm{B}$ and $\mathrm{PM}$ when $w=0, n=0, d=0.5$ and $\beta=0.5$. Cooperation game: (PM,PM) is the unique Pareto efficient SPNE of the game $\left(\Delta_{a}<0, \Delta_{b}>0\right.$ and $\left.\Delta_{c}>0\right)$.

\begin{tabular}{|l|l|l|}
\hline \multicolumn{1}{|r|}{ Firm 2 } & PM & B \\
Firm 1 & & \\
\hline PM & $0.77,0.77$ & $0.98,0.63$ \\
\hline B & $0.63,0.98$ & $0.82,0.82$ \\
\hline
\end{tabular}

Table 6. Payoff matrix (profits) under B and PM when $w=0, n=0, d=-0.7$ and $\beta=0.5$. Prisoner's dilemma: $(\mathrm{PM}, \mathrm{PM})$ is the unique Pareto efficient SPNE of the game $\left(\Delta_{a}<0, \Delta_{b}>0\right.$ and $\left.\Delta_{c}<0\right)$.

Network industry $(n>0)$. The effects of the network externality on the equilibrium outcomes of the game are relevant and thus deserve an ad hoc discussion. Indeed, $n$ plays a twofold role on firms' profits under B and PM. First, the larger the network, the larger the market size and this in turn causes an outward shift in the demand curve implying an increase in the marginal willingness to pay of consumers for any given value of the quantity of the network goods produced by both codetermined and profit maximising firms. Second, it also causes an increase in production because each consumer in a market for a network good benefits from the (positive) experience of all other consumers so that he is willing to pay more than in a non-network market. Interestingly, though $n$ exerts the same qualitative role on firms' profits in both cases of codetermination and profit maximisation, from a quantitative point of view there are remarkable differences. In fact, a positive value of $n$ let the thresholds $d_{a}(\beta, n)$ and $d_{b}(\beta, n)$ come into play in the geometric space $(\beta, d)$. As Panels (b)-(d) in Figures 1 show, when the power of the unions is sufficiently high in the bargaining on prices $\left(\beta<\beta_{T}\right)$, the two thresholds $d_{a}(\beta, n)$ and $d_{b}(\beta, n)$ are not binding and owners will prefer to be profit maximisers rather than becoming bargainers under codetermination. This is because 
they would reduce their profits by choosing to play B. Therefore, the economic mechanisms behind the results when $\beta<\beta_{T}$ are the same as those discussed above in a non-network industry. Differently, when the power of the unions is sufficiently small in the bargaining on prices $\left(\beta>\beta_{T}\right)$, the two thresholds $d_{a}(\beta, n)$ and $d_{b}(\beta, n)$ are binding and owners may choose to become bargainers under codetermination rather than being profit maximisers. In fact, by fixing the values of the strength of the network effect $(n)$ and the bargaining power of the firms $(\beta)$, and letting the degree of product differentiation $(d)$ vary, the model shows how firms' profits change in a network industry and then which kind of paradigm (prisoner's dilemma, coordination game, cooperation game) emerges at the first stage of the game. First, we set $w=0, n=0.5$ and $\beta=0.5$. Then, we let $d$ vary from 0.9 to 0.2 (these examples are illustrated in Tables 7-10). Let us begin the discussion by assuming that consumers perceive products of varieties 1 and 2 as highly substitutable $(d=0.9$, Table 7). In this case, firms do not have an incentive to become bargainers under codetermination. This is because products are close to be substitutes, PM is the dominant strategy and the SPNE of the game is Pareto efficient. If the degree of product differentiation increases $(d=0.7$, Table 8), firms increase profits because their market power becomes larger. Interestingly, the increase in profits under B (due to the sharp increase in production of the codetermined firm) is large enough to prevent PM being the dominant strategy, i.e. each firm has a unilateral incentive to play the same strategy of the rival. However, PM payoff dominates B. However, a further increase in product differentiation ( $d=0.5$, Table 9 ) change the nature of the game that becomes a prisoner's dilemma where $(\mathrm{B}, \mathrm{B})$ is the Pareto inefficient outcome. This is because product differentiation works out in the same direction as codetermination by letting production increase substantially. In a network industry, this increase in larger under B than PM. However, firms are entrapped in a dilemma because they have an incentive to coordinate to play profit maximisation, but no one has a unilateral incentive to deviate from codetermination. Finally, when products are slightly substitutes $(d=0.2$, Table 10) the dilemma is solved and (B,B) becomes the unique Pareto efficient outcome of the 
(coordination) game. In fact, the increase in production under B is larger than the increase in production under PM so that profits in the former case become higher than profits in the latter case. These effects on profits due to product differentiation are magnified by further increases in the strength of the network effects. This result is illustrated in Panels (b)-(d) of Figure 1, where $n$ raises from 0.3 to 0.7 . As can easily be seen by looking at the figures, the parameter space in the plane $(\beta, d)$ for which $(\mathrm{B}, \mathrm{B})$ emerges as the Pareto efficient endogenous outcome of the increases together with $n$. This is because the network externality increases both the market size and the marginal willingness to pay of consumers.

\begin{tabular}{|l|l|l|}
\hline \multicolumn{1}{|l|}{ Firm 2 } & PM & $\mathrm{B}$ \\
\hline Firm 1 & & \\
\hline PM & $0.146,0.146$ & $0.09,0.12$ \\
\hline B & $0.12,0.09$ & $0.08,0.08$ \\
\hline
\end{tabular}

Table 7. Payoff matrix (profits) under B and PM when $w=0, n=0.5, \beta=0.5$ and $d=0.9$. Cooperation game: (PM,PM) is the unique Pareto efficient SPNE of the game $\left(\Delta_{a}<0, \Delta_{b}>0\right.$ and $\left.\Delta_{c}>0\right)$.

\begin{tabular}{|l|l|l|}
\hline \multicolumn{1}{|r|}{ Firm 2 } & PM & B \\
Firm 1 & & \\
\hline PM & $0.275,0.275$ & $0.204,0.271$ \\
\hline B & $0.271,0.204$ & $0.208,0.208$ \\
\hline
\end{tabular}

Table 8. Payoff matrix (profits) under $\mathrm{B}$ and $\mathrm{PM}$ when $w=0, n=0.5, \beta=0.5$ and $d=0.7$. Coordination game: $(\mathrm{PM}, \mathrm{PM})$ and $(\mathrm{B}, \mathrm{B})$ are the Nash equilibria of the game in pure strategies $\left(\Delta_{a}<0, \Delta_{b}<0\right.$ and $\left.\Delta_{c}>0\right)$.

\begin{tabular}{|l|l|l|}
\hline \multicolumn{1}{|c|}{ Firm 2 } & $\mathrm{PM}$ & $\mathrm{B}$ \\
Firm 1 & & \\
\hline PM & $0.33,0.33$ & $0.27,0.35$ \\
\hline B & $0.35,0.27$ & $0.29,0.29$ \\
\hline
\end{tabular}

Table 9. Payoff matrix (profits) under B and PM when $w=0, n=0.5, \beta=0.5$ and $d=0.5$. Prisoner's dilemma: $(\mathrm{B}, \mathrm{B})$ is the unique Pareto inefficient SPNE of the game $\left(\Delta_{a}>0, \Delta_{b}<0\right.$ and $\left.\Delta_{c}>0\right)$.

\begin{tabular}{|l|l|l|}
\hline \multicolumn{1}{|l|}{ Firm 2 } & PM & B \\
Firm 1 & & \\
\hline PM & 0.390 .39 & $0.36,0.33$ \\
\hline B & $0.33,0.36$ & $0.41,0.41$ \\
\hline
\end{tabular}


Table 10. Payoff matrix (profits) under B and PM when $w=0, n=0.5, \beta=0.5$ and $d=0.2$. Cooperation game: $(\mathrm{B}, \mathrm{B})$ is the unique Pareto efficient SPNE of the game $\left(\Delta_{a}>0, \Delta_{b}<0\right.$ and $\left.\Delta_{c}<0\right)$.

\section{Conclusions}

This article aimed at revisiting the existing theoretical literature on codetermination, which has already shown that firms in a quantity-setting duopoly might have an incentive to become bargainers under codetermination rather than remaining profit maximisers, so that codetermination might arise as the endogenous market outcome in a Cournot game. For doing this, the research developed a tractable two-stage duopoly game describing the behaviour of price-setting firms that must choose to be profit maximisers or bargainers under codetermination in a network industry (to account for the striking expansion of networking products in recent years), where consumers perceive products as horizontally differentiated. In sharp contrast with the established literature, it showed that codetermination does never emerge as a Nash equilibrium in a price-setting nonnetwork duopoly, whereas becoming the sub-game perfect Nash equilibrium when prices are strategic substitutes or strategic complements in a network market. Moreover, and more importantly, this equilibrium may be Pareto efficient. This means that codetermination in network industries could be supported by market forces and constitute a Pareto-superior institution.

Conflict of Interest The authors declare that they have no conflict of interest.

\section{References}

Addison, J. T., L. Bellmann, C. Schnabel and J. Wagner (2004), 'The reform of the German works constitution act: a critical assessment’, Industrial Relations 43, 392-420.

Addison, J. T., K. Kraft and J. Wagner (1993), 'German works councils and firm performance', In: B. E. Kaufman and M. M. Kleiner (eds.) Employee Representation: Alternatives and Future Directions, Industrial Relations Research Association, Madison WI, 305-336.

Addison, J. T., C. Schnabel and J. Wagner (1997), 'On the determinants of mandatory works councils in Germany', Industrial Relations 36, 419-445. 
Addison, J. T., C. Schnabel and J. Wagner (1996), 2German works councils, profits and innovation', Kyklos 49, 555-582.

Addison, J. T., C. Schnabel and J. Wagner (2001), 'Works councils in Germany: their effects on establishment performance', Oxford Economic Papers 53, 659-694.

Baraldi, A. L. (2012), 'The size of the critical mass as a function of the strength of network externalities: a mobile telephone estimation', Economics of Innovation and New Technology 21, $373-396$.

Bhattacharjee, T. and R. Pal (2013), 'Network externalities and strategic managerial delegation in Cournot duopoly: is there a prisoners' dilemma?' Review of Network Economics 12, 343-353.

Cable, J. R. and F. R. FitzRoy (1980), 'Productive efficiency, incentives and employee participation: some preliminary results for West Germany’, Kyklos 33, 100-121.

Chirco, A. and M. Scrimitore (2013), 'Choosing price or quantity? The role of delegation and network externalities', Economics Letters 121, 482-486.

Correa-López, M. and R. A. Naylor (2004) 'The Cournot-Bertrand profit differential: a reversal result in a differentiated duopoly with wage bargaining', European Economic Review 48, 681-696.

Doganoglu, T. and L. Grzybowski (2007), 'Estimating network effects in mobile in the mobile telecommunication industry in Germany', Information Economics and Policy 19, 65-79.

Dunlop Commission (1994), Commission on the Future of Worker-Management Relations. Fact Finding Report. Washington, D.C.: U.S. Department of Commerce/U.S. Department of Labor.

Fanti, L. and D. Buccella (2017), 'Bargaining agenda in a unionised monopoly with network effects: when corporate social responsibility may be welfare-reducing', Economia Politica 34, 471489.

Fanti, L. and D. Buccella (2018), 'Profitability of corporate social responsibility in network industries', International Review of Economics, https://doi.org/10.1007/s12232-018-0297-8, forthcoming.

Fanti, L., L. Gori and M. Sodini (2018), 'Codetermination and product differentiation', International Review of Economics \& Finance, https://doi.org/10.1016/j.iref.2018.05.001, forthcoming.

FitzRoy, F. and K. Kraft (1985), Unionization, wages, and efficiency: theories and evidence from the U.S. and West Germany', Kyklos 38, 537-554.

FitzRoy, F. and K. Kraft (1987), 'Efficiency and internal organization: works councils in West German firms', Economica 54, 493-504.

FitzRoy, F. and K. Kraft (1990), Innovation, rent-sharing and the organization of labor in the Federal Republic of Germany', Small Business Economics 2, 95-103.

Frick, B. (2001), ‘Ökonomische Analyse der deutschen Betriebsverfassung', Wittener Diskussionspapiere, Heft No. 89, University of Witten-Herdecke, December. 
Gorton, G. and F. A. Schmid (2004), 'Capital, labor, and the firm: a study of German codetermination', Journal of the European Economic Association 2, 863-905.

Granero, L. M. (2006), 'Codetermination, R\&D, and employment', Journal of Institutional and Theoretical Economics 162, 309-328.

Gürtler, O. and F. Höffler (2015), 'Monitoring of workers and product market competition: the role of works councils', Economic Inquiry 53, 1366-1379.

Hoernig, S. (2012), 'Strategic delegation under price competition and network effects', Economics Letters 117, 487-489.

Katz, M. L. and C. Shapiro (1985), 'Network externalities, competition, and compatibility', American Economic Review 75, 424-440.

Kommission Mitbestimmung (1998), Mitbestimmung und neue Unternehmenskulturen - Bilanz und Perspektiven. Gütersloh: Verlag Bertelsmann Stiftung.

Kraft, K. (1998), 'The codetermined firm in oligopoly', Economics Letters 61, 195-201.

Kreps, D. M. and J. A. Scheinkman (1983), 'Quantity precommitment and Bertrand competition yield Cournot outcomes’, Bell Journal of Economics 14, 326-337.

McCain, R. A. (1980), 'A theory of codetermination', Journal of Economics 1-2, 65-90.

Official Journal (2002), 'Directive 2002/14/EC of the European Parliament and of the Council of 11 March 2002 Establishing a General Framework for Informing and Consulting Employees in the European Community', Official Journal of the European Communities L80 of 23.3.2002, 29-33.

Pal, R. (2014), 'Price and quantity competition in network goods duopoly: a reversal result', Economics Bulletin 34, 1019-1027.

Pal, R. (2015), 'Cournot vs. Bertrand under relative performance delegation: implications of positive and negative network externalities’, Mathematical Social Sciences 75, 94-101.

Singh, N. and X. Vives (1984), 'Price and quantity competition in a differentiated duopoly', RAND Journal of Economics 15, 546-554.

Song, R. and L. F. S. Wang (2017), 'Collusion in a differentiated duopoly with network externalities', Economics Letters 152, 23-26.

Schank, T., C. Schnabel and J. Wagner (2004), 'Works councils - sand or grease in the operation of German firms?' Applied Economics Letters 11, 159-161.

Schnabel, C. and J. Wagner (1994), 'Industrial relations and trade union effects on innovation in Germany', Labour 8, 489-503.

Shy O. (2001), The economics of network industries, Cambridge University Press, Cambridge UK. 